\title{
BMJ Global Health Production costs and potential prices for biosimilars of human insulin and insulin analogues
}

\author{
Dzintars Gotham, ${ }^{1}$ Melissa J Barber, ${ }^{2}$ Andrew Hill ${ }^{3}$
}

To cite: Gotham D, Barber MJ, Hill A. Production costs and potential prices for biosimilars of human insulin and insulin analogues. BMJ Glob Health 2018;3:e000850. doi:10.1136/ bmjgh-2018-000850

Handling editor Nicola Foster

- Additional material is published online only. To view please visit the journal online (http://dx.doi.org/10.1136/ bmjgh-2018-000850).

Received 22 March 2018

Revised 1 July 2018 Accepted 27 July 2018
Check for updates

\section{(C) Author(s) (or their} employer(s)) 2018. Re-use permitted under CC BY-NC. No commercial re-use. See rights and permissions. Published by BMJ.

${ }^{1}$ Faculty of Medicine, Imperial College London, London, UK ${ }^{2}$ Harvard TH Chan School of Public Health, Harvard University, Boston, Massachusetts, USA ${ }^{3}$ Department of Translational Medicine, Liverpool University, Liverpool, UK

Correspondence to Dr Dzintars Gotham; dzintarsgotham@gmail.com

\section{ABSTRACT}

Introduction High prices for insulin pose a barrier to treatment for people living with diabetes, with an estimated $50 \%$ of 100 million patients needing insulin lacking reliable access. As insulin analogues replace regular human insulin $(\mathrm{RHI})$ globally, their relative prices will become increasingly important. Three originator companies control $96 \%$ of the global insulin market, and few biosimilar insulins are available. We estimated the price reductions that could be achieved if numerous biosimilar manufacturers entered the insulin market. Methods Data on the price of active pharmaceutical ingredient (API) exported from India were retrieved from an online customs database. Manufacturers of insulins were contacted for price quotes. Where market API prices could not be identified, prices were estimated based on comparison of similarity, in terms of manufacturing process, with APIs for which prices were available. Potential biosimilar prices were estimated by adding costs of excipients, formulation, transport, development and regulatory costs, and a profit margin.

Results The manufacturing processes for $\mathrm{RHI}$ and insulin analogues are similar. API prices were US\$24 750/kg for RHI, US\$68 757/kg for insulin glargine and an estimated US\$100 000/kg for other analogues. Estimated biosimilar prices were US\$48-71 per patient per year for RHI, US\$49-72 for neutral protamine Hagedorn (NPH) insulin and US\$78-133 for analogues (except detemir: US\$283365).

Conclusion Treatment with biosimilar RHI and insulin NPH could cost $\leq$ US $\$ 72$ per year and with insulin analogues $\leq$ US $\$ 133$ per year. Estimated biosimilar prices were markedly lower than the current prices for insulin analogues. Widespread availability at estimated prices may allow substantial savings globally.

\section{INTRODUCTION}

An estimated 100 million people need insulin worldwide. For people living with type 1 diabetes, a constant supply of insulin is necessary for survival, and insulin is needed for the optimal treatment of many living with type 2 diabetes. ${ }^{1}$ It is estimated that half of these people do not have reliable, affordable access to the medicine, ${ }^{2}$ despite rising demand. ${ }^{3}$ While other factors contribute to the lack
Key questions

What is already known?

- Severe problems in access to affordable insulin exist in low-income and middle-income countries.

- The global insulin market is dominated by three companies, with little competitive biosimilar manufacture.

What are the new findings?

- We estimated that, if there were a competitive biosimilar market, treatment with biosimilar insulins could cost US\$72-133 per year or less.

What do the new findings imply?

- Increasing competition in insulin manufacture could lead to large price reductions, potentially enabling the scale-up of access to treatment.

of global access to insulin, high prices are a significant cause of suffering, catastrophic health expenditures and deaths. ${ }^{4}$ In low-income and middle-income countries (LMICs), medicines are mostly bought out of pocket, in the private sector. ${ }^{5}$

For insulins, the three largest manufacturers of insulins account for $96 \%$ of the global market volume. This oligopoly, regulatory challenges and regular incremental developments in insulins likely explain the lack of a competitive biosimilar market for insulins. ${ }^{167}$

Little has been published on the costs of production of biologics, insulin or its analogues. The aim of this study was to estimate the cost of production and, on this basis, potential prices for biosimilar human insulin and insulin analogues that would be possible with large-scale, competitive manufacturing. Our analysis is made primarily with resource-limited settings in mind and from the perspective of government procurement.

This study was undertaken as part of the Addressing the Challenge and Constraints of Insulin Sources and Supply (ACCISS) study, which aims to improve access to insulin. The 


\section{Competitive formula}

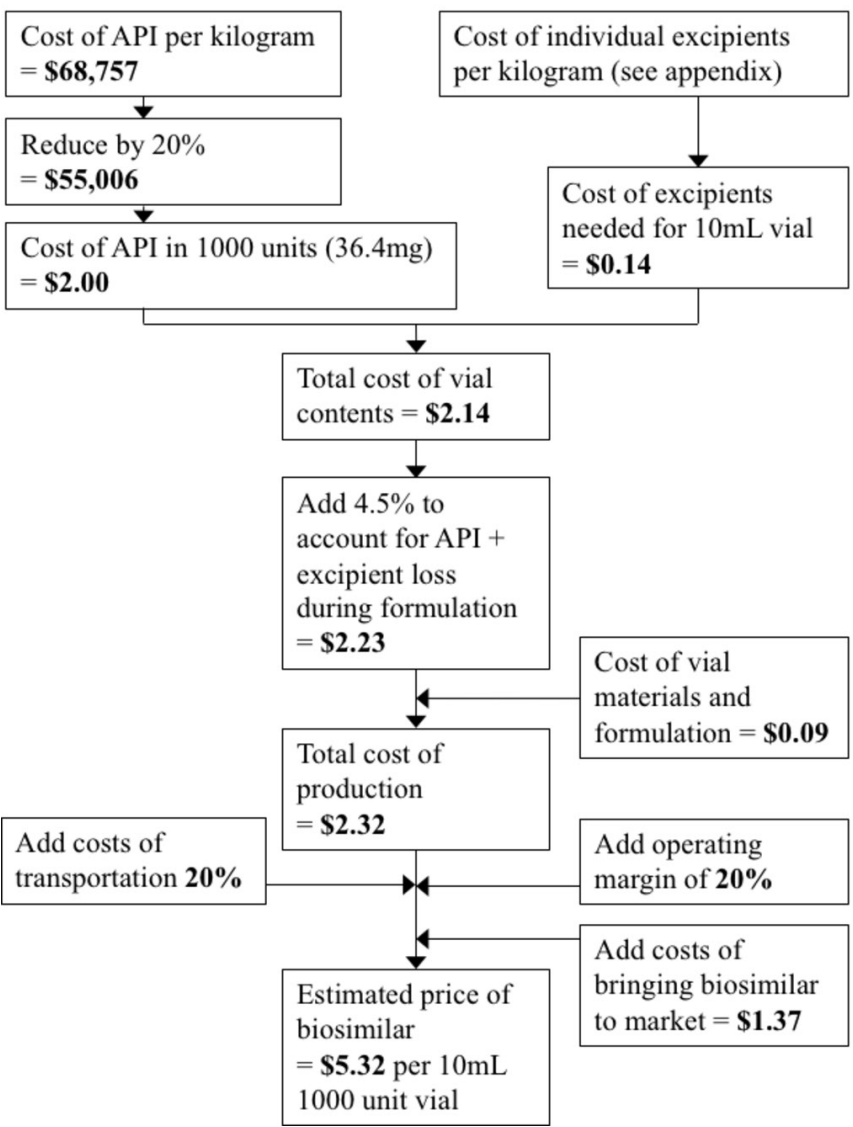

Conservative formula

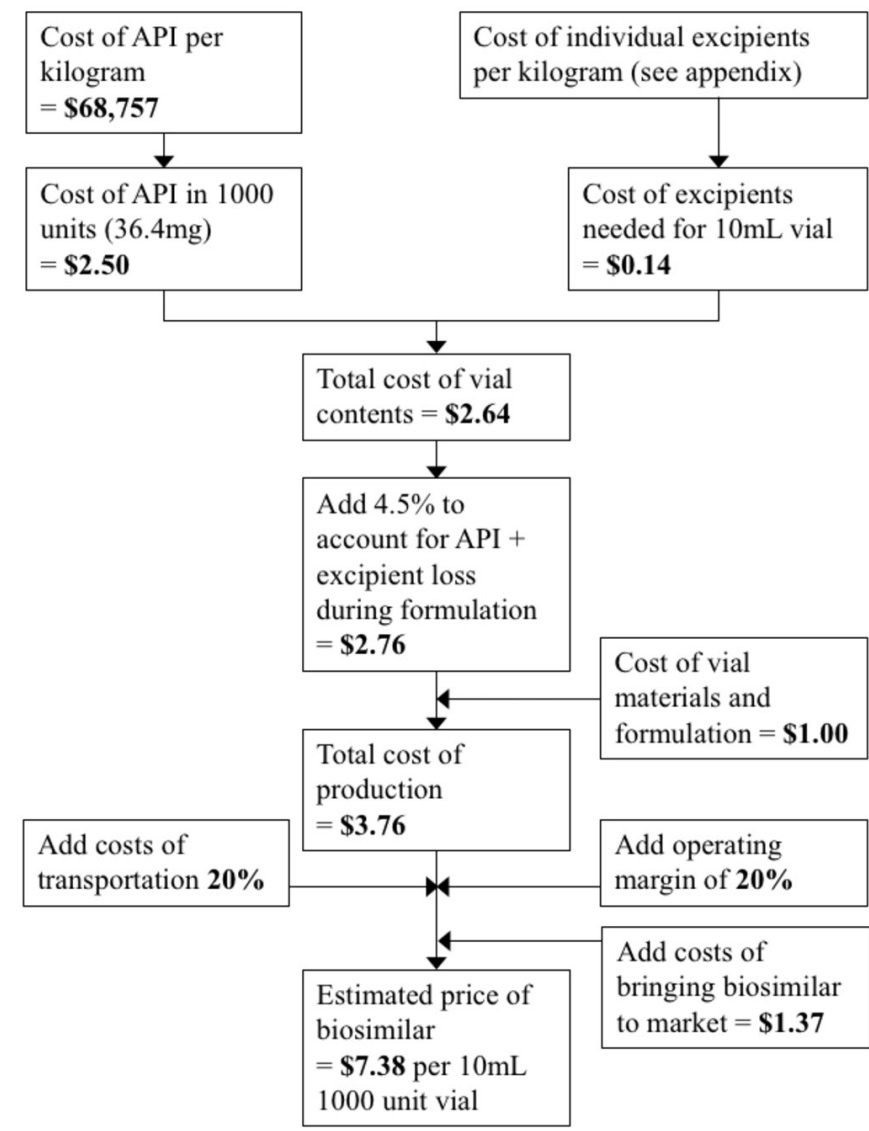

Figure 1 Price estimation formulae for biosimilar insulin glargine. API, active pharmaceutical ingredient.

study is co-led by Health Action International, Geneva University Hospitals and the University of Geneva, and Boston University School of Public Health.

\section{METHODS}

We have previously analysed the costs of production for other medicines. ${ }^{8-10}$ For oral formulations, combining the price of active pharmaceutical ingredient (API) exported from India with assumptions for other production cost components can reliably estimate the prices of medicines manufactured with robust generic competition. ${ }^{8-10}$

We designed formulae for estimating competitive but profitable prices for insulin biosimilars, based on the cost of API and excipients, costs of formulation into phials, development and regulatory cost, and a margin to account for operating expenditures and profit. For two central assumptions, the cost of API and the cost of formulation, we used high and low assumptions, resulting in a range of estimated prices: a 'competitive' formula and a 'conservative' formula. The lower assumption represents a scenario of a well-functioning market of numerous biosimilar manufacturers, and the higher end of the range represents a more conservative estimate. Both formulae, using insulin glargine as an example, are shown in figure 1. Details on the derivation of this formula are described below.
All monetary values are in US dollars.

\section{Costs of API and excipients}

Per-kilogram prices of API exported from India were collected from an online database of exports data published pursuant to Indian customs regulations (www. infodriveindia.com), for the period 1 January 2013 to 1 November 2016. After data cleaning to exclude any non-API product (eg, final finished product shipments) and censoring outliers (a small number of low-volume shipments at very low prices, $\leq$ US\$5 $000 / \mathrm{kg}$ for human insulin and $\leq \mathrm{US} \$ 10 \quad 000 / \mathrm{kg}$ for insulin glargine; see online supplementary figure 1 ), linear regression models were used to calculate average API prices for 1 November 2016 (online supplementary figures 1 and 2).

For insulins where API export data were unavailable or insufficient, we took two further approaches to arrive at an estimated cost of API: direct solicitation of price quotes from API manufacturers, and inference of cost of production based on similarities in method of synthesis to APIs for which price information was available from other sources.

API manufacturers were identified and contacted through the Alibaba and IndiaMART online wholesaler market-places (www.alibaba.com, www.indiamart. com). Internet searches were done to identify additional 
insulin analogue manufacturers, who were contacted by email. Manufacturers identified in a published survey of the global insulin market-place were contacted if their websites indicated that they produce insulin analogues. ${ }^{11}$

In the 'competitive' formula, we subtracted $20 \%$ from the estimated API price to account for prices of exported API likely including numerous mark-ups that could be avoided by inhouse manufacture or by domestic procurement. Although little data are available on API mark-ups, this assumption is based loosely on mark-ups of 15\%-30\% reported for API of HIV medicines. ${ }^{12}$ As the HIV medicines API market is highly competitive, one would expect that this is a low estimate with regard to the less competitive insulin API market, making this assumption conservative in the context of this analysis. The considerations in estimating API price are further outlined later in the methods.

The cost of API required to manufacture one 1000-unit phial was calculated by multiplying the milligram amount contained in 1000 units of the given insulin type (online supplementary appendix) by the per-kilogram API price.

Excipient contents by insulin type, and their average prices, are given in online supplementary appendix.

\section{Manufacturing process}

At the molecular level, insulin analogues are different from human insulin only in a few amino acids (online supplementary figure 3 ). The manufacturing process is very similar for regular human insulin (RHI) and insulin analogues. ${ }^{13} 14$ An insulin precursor, expressed by the altered host cell genome, accumulates in the form of inclusion bodies, which are purified from the bacterial culture. The precursor is then cleaved to insulin in vitro using proteases. ${ }^{3}$ This method is common to RHI and insulin analogues. ${ }^{315-18}$ Similarly, the methods used for purification and refolding of RHI are also viable for insulin analogues. ${ }^{19} 20$

In confidential communications, biosimilar manufacturers confirmed that for recombinant molecules that have a high level of similarity, it is likely that the inherent cost of upstream processing is very similar.

\section{Formulation costs}

A range of estimates for the average cost of formulating API into phials are available.

Studies of antivenom production cost have assumed a formulating cost of US $\$ 1$ and US $\$ 5$ per phial, the latter noting that the estimate was very high. ${ }^{2122}$ A recent study of human papilloma virus vaccine production reported, based on confidential consultation with industry, a wholesale cost of the phial and packaging materials of US\$0.31 per $0.5 \mathrm{~mL}$ phial. ${ }^{23}$

Another source formulation costs are the 'conversion cost norms' published in 2012 by the Indian government, as part of price control legislation. ${ }^{24}$ These norms were used by the government to calculate ceiling prices for medicines until 2013. The conversion, packing and packing material cost 'norms' combined were US $\$ 0.09$ for a $10 \mathrm{~mL}$ phial (online supplementary appendix). The 'norms' prescribed an assumed wastage rate for raw materials during formulation at $4.5 \%$ of API, which we included in our formulae.

Lastly, the prices of the lowest priced products formulated as phials, sold in the UK, can be used as high estimates of their formulating costs (assuming they are not sold at a loss). The prices of the five lowest priced products formulated as phials ranged US\$0.64-0.85/phial (online supplementary appendix).

We assumed a range of cost levels for $10 \mathrm{~mL}$ phial formulation, which include the phial itself and the cost of filling: a higher level of US\$1.00/unit in the 'conservative' formula, based on the prices of the cheapest phial formulation products in the UK, and a lower level of US $\$ 0.09 /$ unit in the 'competitive' formula, based on the values prescribed in the Indian government 'norms'.

\section{Biosimilar development costs}

An estimate by the US Federal Trade Commission put the cost of bringing a biosimilar to market (development, capital expenditure and regulatory costs) at US\$100-200 million in markets with stringent regulatory authorities. ${ }^{25}$ The cost of bringing a biosimilar to market in India has been estimated to be $90 \%$ lower than this. ${ }^{26}$ We assumed that the cost of bringing a biosimilar to market was US $\$ 100$ million, recouped over 5 years. Additionally, we assumed that 1 million patients (or about $5 \%$ of the estimated number of patients with type 1 diabetes globally) ${ }^{1}$ would purchase insulin from any new biosimilar manufacturer-approximately equivalent to the yearly rate at which insulin analogues have displaced human insulin from the market in high-income countries. ${ }^{11}$ Therefore, an additional US $\$ 20$ per patient per year would be added to the cost of production, for the first 5 years that the hypothetical biosimilar is available.

\section{Other costs for mass production}

Costs of excipients were added based on prices listed online by large chemical manufacturers and typical excipient composition (online supplementary appendix). We added an additional $20 \%$ margin for operating expenditures and profit. We undertook a sensitivity analysis on these cost assumptions.

An analysis by IMS Health estimated that for diabetes medicines, importation and distribution costs added $23 \%$ to the manufacturer price in Brazil, 23\% in India, $41 \%$ in Indonesia and $11 \%$ in South Africa. ${ }^{27}$ Therefore, to allow comparison of estimated prices with reported government procurement prices, we added $20 \%$ to represent the cost of importation and distribution.

\section{Estimated biosimilar prices based on companies' reported costs of production}

Some insulin manufacturers report the total expenses in cost of production (termed 'cost of goods sold') as a percentage of sales. While it is not possible to definitively calculate per-unit costs of production from these 
reported percentages, we separately estimated the cost of production based on these reported expenses (online supplementary appendix). Sufficient data were available only for Novo Nordisk, but not for Sanofi or Lilly.

\section{Patient and public involvement}

Neither patients nor the public were involved in the research.

\section{RESULTS}

\section{Price of API exported from India}

Sufficient data on the price of exported API were available for RHI and insulin glargine.

RHI had an average price of US $\$ 32228 / \mathrm{kg}$ on 1 November 2016. Shipments to the USA demonstrated two 'plateaus' at US\$70 000/kg and US\$58 000/ kg price levels, both price levels significantly above the pricing of exports to other regions (online supplementary figure 1). Another plateau was visible for exports to Mexico, at US\$26 000-28 000/ $\mathrm{kg}$. The consistency of the price and order sizes within these plateaus suggests recurring orders between individual buyers/manufacturers. If shipments to the USA were excluded from the data set, linear regression yielded an estimated price of US\$24 750/ kg (decreasing by an average $18 \%$ yearly). This value, after removing exports to the USA, was used in production cost estimates. The volume of RHI API exported from India roughly doubled during the time frame studied, from 484 $\mathrm{kg}$ exported in 2013 to $793 \mathrm{~kg}$ in 2016 up to 1 November, the latter equivalent to about 1.6 million patient-years of treatment or 22.7 million 1000-unit phials.

The linear regression model for insulin glargine gave an average price of US\$68 $757 / \mathrm{kg}$ (decreasing by an average of $27 \%$ yearly) on 1 November 2016 (online supplementary figure 2). A plateau was evident for exports to Mexico at around US\$80 000/kg.

\section{API price estimation for insulins with insufficient data on API exports}

API price quotes from biosimilar manufacturers were received for insulin aspart and none for other analogues.

\section{Insulin NPH}

In insulin neutral protamine Hagedorn (NPH), protamine and insulin are combined as crystals in a molar ratio of approximately 8.5:1 (online supplementary appendix). Protamine sulfate is available commercially for US\$6550-10 800/ kg. As the molecular weight of RHI and protamine sulfate is similar, insulin NPH API cost can be estimated by assuming it is $89 \%$ by mass composed of RHI costing US $\$ 24750 / \mathrm{kg}$ and $11 \%$ protamine sulfate costing US $\$ 10800 / \mathrm{kg}$. This yields a per-kilogram insulin NPH API price of US\$23 282.

\section{Insulin aspart}

Insulin aspart is different from RHI in 1 of 51 amino acids. Quotes were received from two manufacturers for insulin aspart, at US\$87 720 and US\$116 108 per kilogram. Both manufacturers were based in China. Based on the quotes received from the manufacturers, we estimated an API cost for insulin aspart of US $\$ 100000 / \mathrm{kg}$. This is about four times our estimate (based on observed shipments) for RHI.

Insulin lispro and insulin glulisine

Insulin lispro and glulisine are each different from RHI in 2 of 51 amino acids. Lispro was the first analogue to be developed, and its manufacturing process for insulin lispro is nearly identical to that of RHI. ${ }^{14}$ We assumed that their API costs are the same as that for insulin aspartUS $\$ 100000 / \mathrm{kg}$.

Insulin detemir and insulin degludec

Insulin detemir and insulin degludec differ from RHI by their lack of the last residue on $\mathrm{B}$ chain and the attachment of a fatty acid group in its place. For originators detemir and degludec, the addition of the fatty acid groups is done in vitro, after purifying from the producing cell a human insulin-like precursor modified to lack the $\mathrm{B} 30$ residue. ${ }^{18} 28$ The fermentation and recovery aspects are common to RHI, detemir and degludec production. ${ }^{28}$ The fatty acids are commercially available at low cost. Given the small difference in amino acid sequence, the relatively simple process of adding fatty acid chains and the low cost of reagents, we assumed the cost of detemir and degludec API to be equal to that for the aspart, lispro and glulisine analogues. However, due to its dosage in milligram terms being three times that of the other insulin analogues, the estimated price for insulin detemir was significantly higher (see below).

\section{Final estimated prices}

Final price estimates are given in table 1, and a full costing breakdown is available in online supplementary appendix. Assuming a dosage of 40 units/day (WHO defined daily dose for insulin), these estimated prices translate to a cost per patient per year of US\$48-133, except for the cost of detemir, at US\$283-365 per year.

The estimated biosimilar prices are set in context in figure 2, where they are compared with recent government procurement prices in various countries reported by the ACCISS study ${ }^{4}$, as well as UK government-purchase prices reported in the British National Formulary and US prices government-purchase prices reported by the US Veterans' Affairs Committee. ${ }^{29}{ }^{30}$ Current prices of RHI were at a median of 1.2-1.8 times the estimated prices. Current prices of insulin glargine were at a median of 5.6-7.8 times the estimated prices, insulin lispro prices were at 2.7-3.7 times the estimated prices, and insulin aspart prices were at 2.6-3.5 times the estimated prices. It is important to note that the countries included in price comparisons differ by type of insulin, and government procurement prices reported by the ACCISS study are for any presentation (phial, prefilled pen, cartridge), while our estimated prices are for phials only. 


\begin{tabular}{|c|c|c|c|c|c|c|}
\hline Compound & $\begin{array}{l}\text { Price of API per } \\
\text { kilogram (US\$) }\end{array}$ & $\begin{array}{l}\text { Typical dose } \\
\text { per day* }(\mathbf{m g})\end{array}$ & $\begin{array}{l}\text { API cost per } \\
\text { day (US\$) }\end{array}$ & $\begin{array}{l}\text { Estimated cost } \\
\text { of production } \\
\text { for } 10 \mathrm{~mL}(1000 \\
\text { units) phial (US\$) }\end{array}$ & $\begin{array}{l}\text { Estimated price } \\
\text { for } 10 \mathrm{~mL}(1000 \\
\text { units) phial (US\$) }\end{array}$ & $\begin{array}{l}\text { Estimated } \\
\text { price per year } \\
\text { (US\$) }^{\star}\end{array}$ \\
\hline Regular human insulin & 24750 & 1.40 & 0.03 & $2.28-3.37$ & $3.29-4.86$ & $48-71$ \\
\hline Insulin NPH & 23282 & 1.56 & 0.04 & $2.32-3.42$ & $3.35-4.93$ & $49-72$ \\
\hline Glargine & 68757 & 1.46 & 0.10 & $3.69-5.13$ & $5.32-7.38$ & $78-108$ \\
\hline Lispro & 100000 & 1.40 & 0.14 & $4.52-6.16$ & $6.51-8.87$ & $95-130$ \\
\hline Aspart & 100000 & 1.40 & 0.14 & $4.51-6.16$ & $6.50-8.86$ & $95-129$ \\
\hline Glulisine & 100000 & 1.40 & 0.14 & $4.47-6.11$ & $6.44-8.80$ & $94-128$ \\
\hline Detemir & 100000 & 5.68 & 0.57 & $13.47-17.35$ & $19.40-24.99$ & $283-365$ \\
\hline Degludec & 100000 & 1.46 & 0.15 & $4.66-6.34$ & $6.71-9.13$ & $98-133$ \\
\hline
\end{tabular}

${ }^{*}$ Assuming 40 units used per patient per day.

$\mathrm{API}$, active pharmaceutical ingredient; NPH, neutral protamine Hagedorn.

\section{Sensitivity analysis}

Across the different potential assumptions discussed in this analysis, the final estimated prices were most sensitive to the assumption regarding phial formulation and packaging cost, followed by API cost (table 2). If the assumed cost of phial materials and formulation is changed from the current 'competitive formula' assumption (US $\$ 0.09$ / phial) to the highest available estimate (US\$5.00/phial), the estimated price of RHI triples from US $\$ 48 /$ year to US $\$ 151$ year, but the prices of analogues approximately double from US\$78-98/year to US\$181-201/year (except detemir).

Halving and doubling the estimated API price resulted in changes of $-17 \%$ to $+88 \%$. Changing the assumed operating margin from the base case $20 \%-10 \%$ or $50 \%$ resulted in changes to estimated price of $-8 \%$ to $+25 \%$.

\section{Estimated biosimilar prices based on companies' reported costs of production}

Based on these figures, we calculated an estimated cost of production of US\$1.45-9.64 per item, depending on assumptions regarding the number of units sold and the proportion of items sold that contained 300 vs 1000 units of insulin (online supplementary appendix).

\section{DISCUSSION}

It may be possible to profitably manufacture biosimilars of recombinant human insulin and insulin NPH for a price of US $\$ 72$ per patient per year or less. Biosimilars of insulin analogues-lispro, aspart, glargine, glulisine and degludec - may be profitably manufactured for prices of US\$133 per patient per year or less. With high levels of competition, our estimates suggested that prices could fall to US $\$ 48$ per year for biosimilars of human insulin and US\$78-98 for insulin analogues (table 1). Comparison of estimated prices with recent government procurement prices suggests that robust competition in the human insulin and insulin analogue market would lead to sizeable savings in most countries and that current manufacturers could set significantly lower prices while still making a profit (figure 2).

Price estimates were based on observed prices of API exported from India for RHI, NPH and insulin glargine. For other analogues, assumptions for API costs were based on quotes from biosimilar manufacturers and similarities in structure and process. Given the high level of similarity in molecular structure and manufacturing process, the relatively high price quoted by biosimilar manufacturers for insulin aspart compared with RHI is likely due to differences in demand volumes. Nevertheless, we conservatively assumed that other analogues for which export data were not available were priced similarly. Our estimated prices included a profit margin, a margin to account for transportation and import costs, and a conservative estimate for biosimilar development cost, which we assumed would be recouped equally in resource-limited and high-income markets (rather than at differentiated margins). As a point of comparison, we also estimated the cost of production per item using expense reports from Novo Nordisk (online supplementary appendix), which yielded estimates that were similar to the estimates made based on API prices.

The assumed API costs were in the middle of the range of production costs estimated for monoclonal antibodies (US\$20 000-300 000/kg), which are much larger molecules and whose manufacture is more complex. ${ }^{1831}$ The prices estimated for RHI were in some cases higher than the prices reported in the ACCISS study (figure 2A). ${ }^{4}$ This finding likely reflects a combination of conservative assumptions and 'front-loading' of the costs of bringing a biosimilar to the market (we assumed that these sunk costs were to be recouped in the first 5 years of sales), which the three big current manufacturers will likely have already recouped many years ago. This finding also suggests that in a small number of countries, insulin biosimilars may initially be marginally more expensive than the lowest prices offered by originators in some contexts. In some 
A

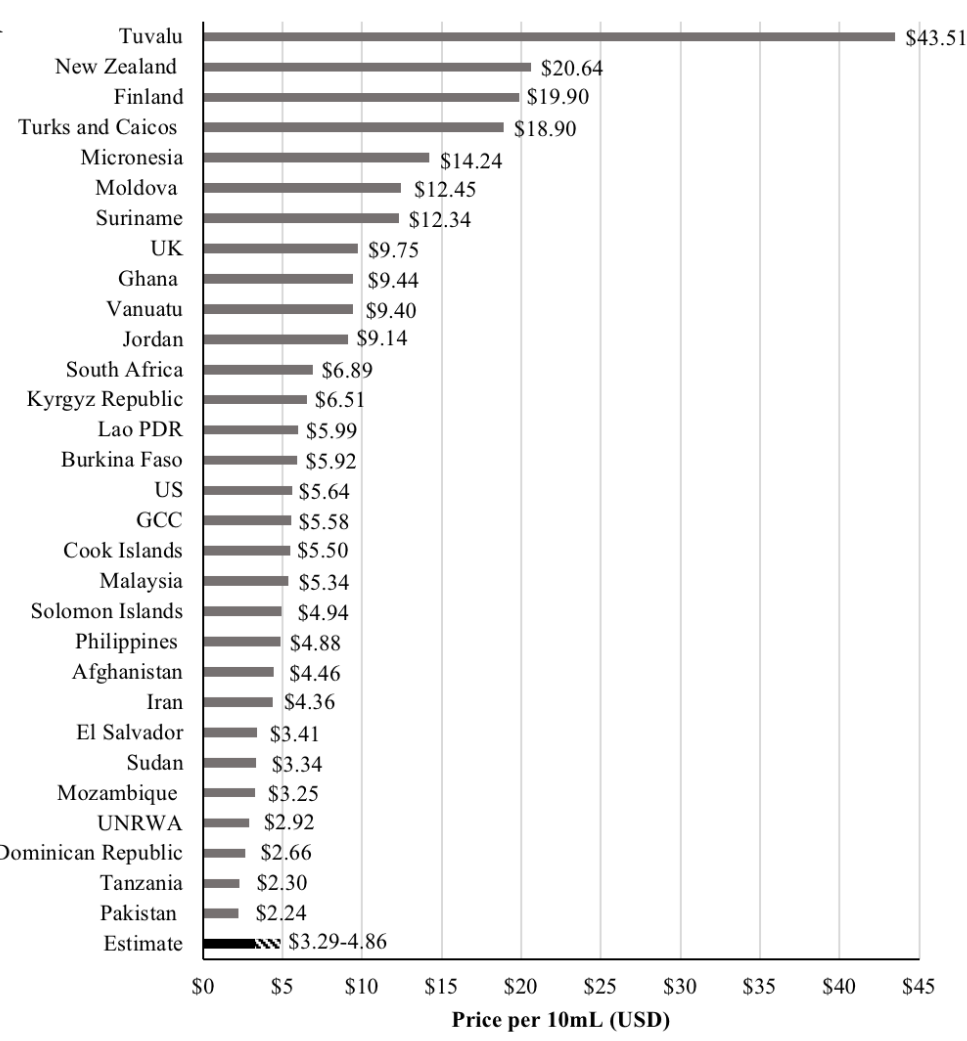

$\mathrm{B}$

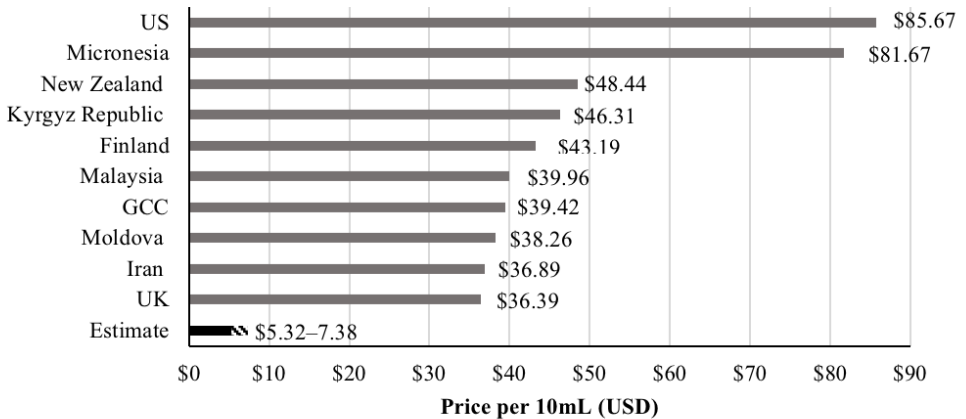

$\mathrm{C}$

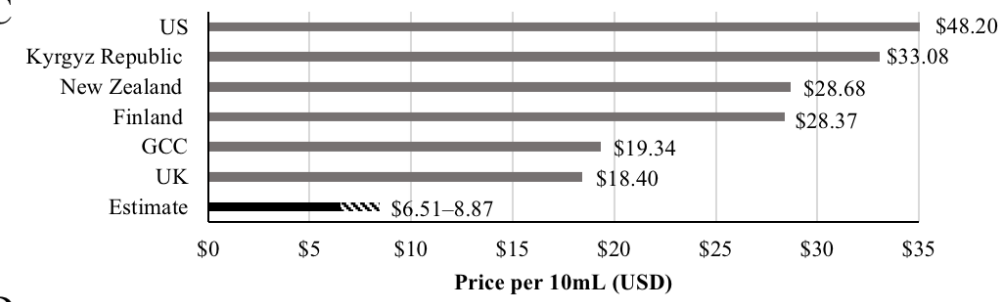

$\mathrm{D}$

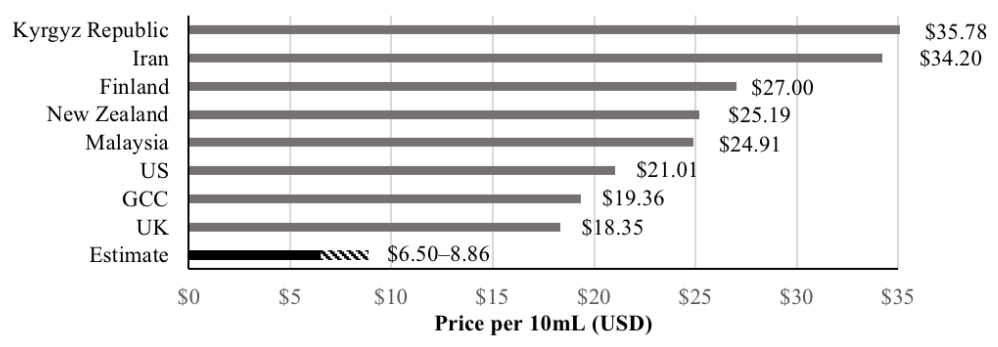

Figure 2 Prices of insulins in selected countries: (A) regular human insulin, (B) insulin glargine, (C) insulin lispro and (D) insulin aspart. Prices are for $10 \mathrm{~mL}$ (1000 units) in government procurement and for any presentation. Data from the ACCISS study ${ }^{4}$, the British National Formulary, and the National Acquisition Center (CCST) Pharmaceutical Catalog Search tool. ACCISS, Addressing the Challenge and Constraints of Insulin Sources and Supply; GCC, Gulf Cooperation Council; PDR, People's Democratic Republic; UNRWA, the United Nations Relief and Works Agency for Palestine Refugees in the Near East. 


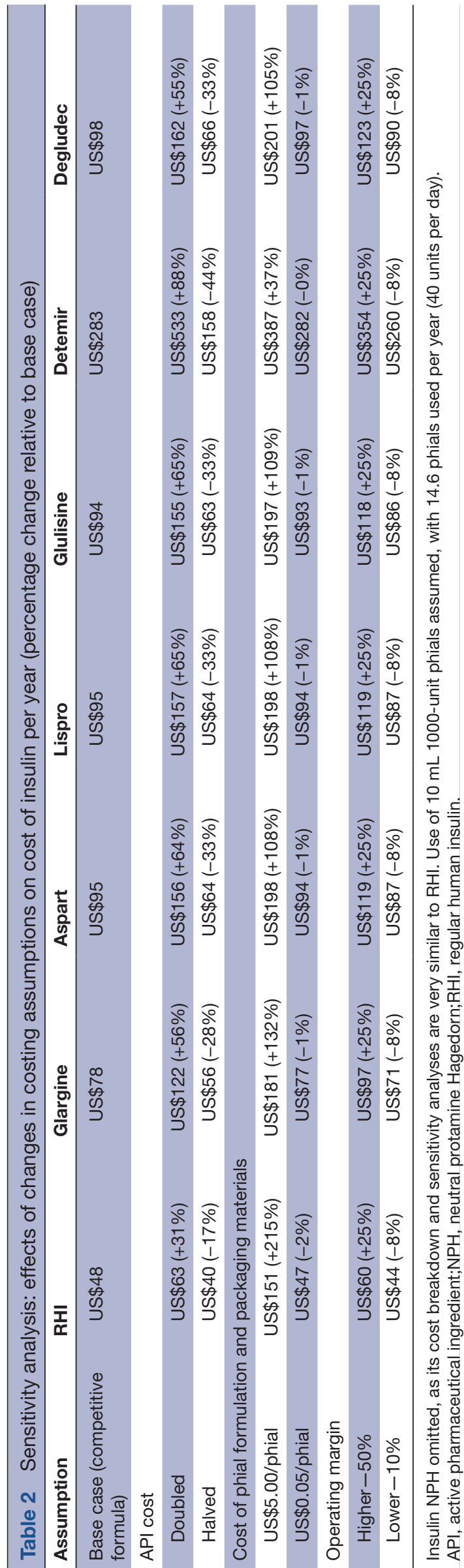

countries, where originators offer low prices, in order to encourage a competitive and sustainable market for insulins, new market entrants may need to be supported by procuring at prices that are slightly above the lowest prices available from an originator (such strategies are well established in HIV, tuberculosis and malaria ${ }^{32}$ ).

Our estimated prices demonstrate that the price of biosimilar of insulin analogues (except detemir) would not be expected to be more than two times that of RHI, even given conservative assumptions regarding analogue API prices based on low demand volumes (table 1). Estimated prices for insulin analogues were 1.9-2.0 times higher than the estimated price for RHI (except detemir: 5.1-5.9 times higher). This price differential is far smaller than the differentials currently seen in LMIC markets (figure 2). Due to the high level of similarity in molecular structure and manufacture processes, the difference in API price between RHI and analogues is likely explained by the relatively young biosimilars market, differences in demand volumes, different levels of process optimisation, and other overheads such as regulatory costs. If this is true, then the price of API for analogues could rapidly fall to near the price of RHI API. Due to increasing rates of type 1 and 2 diabetes, global demand for insulin API could rise to more than $16000 \mathrm{~kg}$ per year by $2025 .{ }^{13}$ In order to meet this increasing demand, new manufacture facilities will likely need to be built. The cost of these facilities is included in our estimated prices, as it is included in the assumed costs of bringing a biosimilar to market. Governments may offer additional incentives to develop local biosimilar manufacturing capacity, for example, in the form of tax incentives.

Our estimates suggest that yearly treatment with biosimilars of human insulin or insulin analogues could have drug costs similar to, or lower than, current lowest prices for first-line treatments for HIV, for which major international treatment programmes have led to 19.5 million people receiving treatment in $2016 .{ }^{33}{ }^{34} \mathrm{At}$ the estimated prices, comprehensive treatment of an estimated 19 million people living with type 1 diabetes would cost US\$0.9-1.4 billion per year using biosimilar human insulin and insulin NPH, and US\$1.5-2.5 billion using biosimilar insulin analogues other than detemir. For comparison, LMIC antiretroviral sales were estimated to be US $\$ 1.8$ billion in $2014 .{ }^{35}$ With the global insulin market estimated to be US $\$ 32$ billion in $2019,{ }^{4}$ significant savings would appear to be possible if insulins became available at the prices estimated in this analysis.

Prices for the API are falling: even at the low volumes currently being exported from India, the linear regression models showed $18 \%$ yearly decrease in price for exported human insulin API and 27\% yearly decrease for insulin glargine. It would be reasonable to expect that with increasing biosimilar production, API prices will continue to fall. More than half of relevant patents protect devices related to insulin treatment, rather 
than API, and most patents on insulin analogue APIs have expired or are expiring by 2020 in the USA. ${ }^{3637}$

The need for price reductions for insulin analogues is made more pressing by the fact that analogues are replacing RHI in high-income countries and a growing number of middle-income countries, despite a lack of evidence for significant clinical benefit. ${ }^{1}$ If this trend continues, markets for RHI may collapse. Simultaneously, the volume demand for insulins is expected to rise dramatically in the coming decades. ${ }^{3}$

To stimulate the development of a competitive biosimilars market for insulins, a range of procompetitive policy approaches are available to governments and the international community. These include tenders and special incentives for the first non-originator market entrant. International pooled procurement mechanisms like the Pan American Health Organization's Revolving Fund and Strategic Fund could also play a role in supporting a competitive biosimilar insulin market for supply of LMICs. Although current analyses suggest that intellectual property (IP) does not pose a significant barrier to biosimilar insulins, if IP barriers did become apparent in some cases, voluntary or compulsory licences could be sought to enable biosimilar production. ${ }^{15}$ Lastly, technology transfer from originator companies to LMIC manufacturersie, the transfer of know-how regarding manufacturing processes and/or the transfer of materials such as cell banks-would likely significantly lower the barrier to developing a biosimilar. Other measures to control insulin prices, which are discussed in more detail elsewhere, would remain important, including consideration of import taxes, and controls on distributor and pharmacy mark-ups. ${ }^{1}$

Earlier commentators have predicted that the price reductions offered by biosimilars will be modest, with many giving estimates for expected price reductions in the range of $10 \%-70 \%{ }^{38}$; however, the biosimilar market is very young, with a low number of competitive manufacturers for individual products. Recently price reductions as great as $70 \%$ have been seen for biosimilar infliximab. ${ }^{39}$ Price reductions for the first insulin biosimilar available in the USA or Europe-a biosimilar of insulin glargine-have also arguably been modest (a second biosimilar has been approved in the European Union in the past few months, but pricing data are not yet available), ${ }^{40}$ although large price reductions would not be expected with the first non-originator market entrant. As a point of comparison, the price estimated in this analysis for insulin glargine is about $60 \%-80 \%$ lower than prices of originator insulin glargine in high-income countries. ${ }^{40}$ Our cost-based estimates thus lie at the higher end of the range of the price reductions predicted earlier by commentators. ${ }^{38}$

In some jurisdictions, there are insulin-specific regulatory requirements that are less demanding than for biosimilars more broadly. ${ }^{41}$ However, as for all biosimilars, there are challenges with impurities and within-product variability. ${ }^{38} 42$ Indian companies have previously sought, and failed, to gain market approval for biosimilar insulins in the European market. ${ }^{7}$ To address these issues, the WHO is exploring the possibility of using the prequalification programme for insulins. ${ }^{43}$

\section{Limitations}

The key limitation of our analysis is the large number of assumptions that were necessary in order to arrive at estimates of biosimilar prices.

There are expenses in biosimilar manufacture that are not individually considered in this analysis, such as capital expenditures, quality assurance and control, registration costs, costs associated with adherence to manufacturing regulations, and maintaining an aseptic manufacturing process. However, we have included a conservative assumption for the total costs of bringing a biosimilar to market. In addition, many of these costs are likely to be already represented in the estimated costs of API, which are based on completed sales and/ or price quotes. By removing the cost of paying a profit margin to a third-party API manufacturer, inhouse production of API or domestic rather than international procurement would likely reduce costs and result in lower prices, or afford manufacturers higher profit margins, than the prices estimated in this analysis. Similarly, the assumed cost of formulation for the "conservative' formula is based on sales prices of finished phial products, which would also include capital, quality control and operating expenditures.

Our estimated prices assume purchase directly from the manufacturer, including a mark-up for transportation costs. Final prices to patients or health systems may include additional mark-ups added during the supply chain. ${ }^{1}$ These mark-ups will vary between countries, as they may be subject to local negotiations, regulations and other factors. In some cases, these additional mark-ups can be very large. Beyond a margin for import tariffs and transport, we have not included estimates for these mark-ups as our estimates (and comparisons with current prices) are made from the perspective of government procurement. High supply chain mark-ups, where they exist, would be a priority target for cost-containment measures.

We estimated sustainable prices for the $10 \mathrm{~mL}$ phial formulation and did not estimate the price of pen or cartridge formulations. This limits the ability to compare estimated prices with current lowest prices as reported by the ACCISS study, as the figures in the ACCISS study are reported for insulins in any formulation $^{4}$ (figure 2). Our analysis is primarily focused on resource-limited countries, where the majority of insulins are formulated in phials. ${ }^{4}$ The added costs for producing other formulations, such as self-injections pens, could be the subject of future work.

\section{CONCLUSION}

Given a robust, competitive biosimilars market, it may be possible to profitably manufacture biosimilar insulins at 
prices of US $\$ 72$ per year or less for human insulin and US $\$ 133$ per year or less for insulin analogues. In order for this to happen, multiple competitors would likely need to enter the market. Production costs are only one element and, as with HIV/AIDS, an important step will be political recognition that diabetes can benefit from large, international treatment expansion plans, as well as regulatory coordination and market shaping. The WHO prequalification of biosimilar insulins, if and when realised, is likely to significantly encourage global competition, but companies need to be sure that the insulin they produce will be purchased. It could be posited that more insulin would be purchased globally if biosimilars became available at the estimated prices, thereby expanding the market.

Acknowledgements We thank Dr David Beran and Dr Margaret Ewen for their support and thoughtful comments on drafts of the manuscript.

Contributors DG designed the study. DG and MJB collected and analysed the data and drafted the manuscript. AH provided critique of the manuscript.

Funding This analysis was funded by the ACCISS study, which is funded by The Leona M and Harry B Helmsley Charitable Trust and Stichting ICF.

Disclaimer The funder was not involved in the conduct of the study or the decision to submit. Representatives of the ACCISS study provided comments on the manuscript but did not make the final decision to submit for publication. The analysis in this paper is that of the authors alone and does not necessarily reflect the views of the Helmsley Charitable Trust or Stichting ICF. All references and conclusions are intended for educational and informative purposes and do not constitute an endorsement or recommendation from the Helmsley Charitable Trust or Stichting ICF.

Competing interests None declared.

Patient consent Not required.

Provenance and peer review Not commissioned; externally peer reviewed.

Data sharing statement Further data may be obtained from the corresponding author.

Open access This is an open access article distributed in accordance with the Creative Commons Attribution Non Commercial (CC BY-NC 4.0) license, which permits others to distribute, remix, adapt, build upon this work non-commercially, and license their derivative works on different terms, provided the original work is properly cited, appropriate credit is given, any changes made indicated, and the use is non-commercial. See: http://creativecommons.org/licenses/by-nc/4.0

\section{REFERENCES}

1. Beran D, Ewen M, Laing R, 2015. Access to insulin - current challenges \& constraints. http://apps.who.int/medicinedocs/ documents/s22269en/s22269en.pdf (accessed 27 Jul 2017).

2. ACCISS/HAI, 2015. Inequities and inefficiencies in the global insulin market [article online]. http://haiweb.org/wp-content/uploads/ 2015/11/ACCISS-Fact-Sheet-1-Inequalities-in-Insulin-Market.pdf (accessed 17 Jun 2017).

3. Baeshen NA, Baeshen MN, Sheikh A, et al. Cell factories for insulin production. Microb Cell Fact 2014;13:141.

4. Ewen M, Beran D, Joosse H-J, 2016. Insulin prices profile [article online]. http://haiweb.org/wp-content/uploads/2016/04/ACCISSPrices-report_FINAL-1.pdf (accessed 27 Jul 2017).

5. Wirtz VJ, Hogerzeil HV, Gray AL, et al. Essential medicines for universal health coverage. Lancet 2017;389:403-76

6. Greene JA, Riggs KR. Why is there no generic insulin? Historical origins of a modern problem. N Engl J Med 2015;372:1171-5.

7. Heinemann L. Biosimilar insulin and costs. J Diabetes Sci Technol 2016;10:457-62.

8. Hill A, Simmons B, Gotham D, et al. Rapid reductions in prices for generic sofosbuvir and daclatasvir to treat hepatitis C. J Virus Erad 2016;2:28-31.

9. Gotham D, Fortunak J, Pozniak A, et al. Estimated generic prices for novel treatments for drug-resistant tuberculosis. J Antimicrob Chemother 2017;72:dkw522-52.
10. Hill A, Barber M, Gotham D. Generic treatments for HIV, HBV, HCV, TB could be mass produced for $<\$ 90$ per patient. $J$ Int AIDS Soc 2017;20(Suppl 50.

11. Wirtz VJ, 2016. Insulin market profile [article online]. http://haiweb. org/wp-content/uploads/2016/04/ACCISS_Insulin-Market-Profile_ FINAL.pdf (accessed 27 Jul 2017).

12. UNITAID. 2014. HIV medicines technology and market landscape. 1st Edition. http://unitaid.org/images/marketdynamics/publications/HIVMeds-Landscape-March2014.pdf (accessed 30 Jun 2018).

13. Sandow J, Landgraf W, Becker R, et al. Equivalent recombinant human insulin preparations and their place in therapy. Eur Endocrinol 2015;11:10.

14. Chance RE, Glazer NB, Wishner KL. Manufacturing process for insulin lispro. In: Walsh G, Murphy B, Biopharmaceuticals, an industrial perspective. Dordrecht, 1999:156-9.

15. Sreenivas S, Krishnaiah SM, Govindappa N, et al. Enhancement in production of recombinant two-chain Insulin Glargine by overexpression of Kex2 protease in Pichia pastoris. Appl Microbiol Biotechnol 2015;99:327-36.

16. Zimmerman RE, Stokell DJ, Akers MP. Aspart proinsulin compositions and methods of producing aspart insulin analogs therefrom [patent], 2012.

17. European Medicines Agency. 2017.Apidra, INN-insulin glulisine [article online]. http://www.ema.europa.eu/docs/en_GB/document library/EPAR - Scientific Discussion/human/000557/WC500025246. pdf (accessed 28 Jul 2017).

18. European Medicines Agency. 2017.Tresiba : EPAR - Public assessment report [article online]. http://www.ema.europa.eu/ docs/en_GB/document_library/EPAR_-_Public_assessment_report/ human/002498/WC500139010.pdf (accessed 28 Jul 2017).

19. Edupuganti BR, Jagirdar H, Kumar M. Processes for refolding of insulin [patent], 2011.

20. Coleman MP, Ortigosa AD, Sleevi MC. Process for purifying insulin and analogues thereof [patent], 2014.

21. Morais V, Massaldi $\mathrm{H}$. Economic evaluation of snake antivenom production in the public system. J Venom Anim Toxins Incl Trop Dis 2006;12:497-511.

22. Laustsen $\mathrm{AH}$, Johansen $\mathrm{KH}$, Engmark $\mathrm{M}$, et al. Recombinant snakebite antivenoms: a cost-competitive solution to a neglected tropical disease? PLoS Negl Trop Dis 2017;11:e0005361.

23. Clendinen $\mathrm{C}$, Zhang $\mathrm{Y}$, Warburton $\mathrm{RN}$, et al. Manufacturing costs of HPV vaccines for developing countries. Vaccine 2016;34:5984-9.

24. National Pharmaceutical Pricing Authority. 2017.S.O. 3013(E) [article online]. http://www.nppaindia.nic.in/norms/press27dec12/so3013e27-12-12.html (accessed 27 Jul 2017).

25. Federal Trade Commission Report. 2009.Emerging health care issues: follow-on biologic drug competition. https://www.ftc. gov/reports/emerging-health-care-issues-follow-biologic-drugcompetition-federal-trade-commission-report (accessed 28 Feb 2018).

26. Bourgoin AF. 2011. What you need to know about the follow-on biologic market in the U.S: implications, strategies, and impact. Thomson Reuters. http://www.aff.cz/wp-content/uploads/2011/05/ White-paper-on-bios-Reuters.pdf (accessed 28 Feb 2018).

27. IMS Institute for Healthcare Informatics, 2014. Understanding the pharmaceutical value chain. https://www.imshealth.com/files/web/ IMSHInstitute/HealthcareBriefs/Understanding_Pharmaceutical Value_Chain.pdf. (accessed 27 Jul 2017).

28. European Medicines Agency. 2017.Levemir, INN-insulin detemir. Scientific discussion [article online]. http://www.ema.europa.eu/ docs/en_GB/document_library/EPAR_-_Scientific_Discussion/ human/000528/WC500036658.pdf (accessed 28 Jul 2017).

29. British National Formulary, 2018. Available from: https://bnf.nice.org. uk/

30. National Acquisition Center (CCST), 2018. Pharmaceutical Catalog Search tool. Available from: https://www.va.gov/nac/Pharma/List

31. Kelley $\mathrm{B}$. Industrialization of $\mathrm{mAb}$ production technology: the bioprocessing industry at a crossroads. MAbs 2009;1:443-52.

32. The Global Fund. 2015.34th board meeting: market shaping strategy. https://www.theglobalfund.org/media/4200/bm34_17-anne x1marketshapingstrategy_paper_en.pdf (accessed 28 Feb 2018).

33. UNAIDS. 2017.Fact sheet: latest statistics on the status of the AIDS epidemic [article online] http://www.unaids.org/sites/default/files/ media_asset/UNAIDS_FactSheet_en.pdf (accessed 24 Jul 2017)

34. Médecins Sans Frontières. 2016.Untangling the web of antiretroviral price reductions, 18th Edition [article online]. https://www. msfaccess.org/sites/default/files/HIV_report_Untangling-the-web18thed ENG_2016.pdf. (accessed 27 Jul 2017).

35. Clinton Health Access Initiative. 2015.ARV Market Report: The State of the Antiretroviral Drug Market in Low-and Middle-Income Countries, 2014-2019. http://www.clintonhealthaccess.org/content/ 
uploads/2015/11/CHAI-ARV-Market-Report-2015_FINAL.pdf. (access 27 Jul 2017).

36. Luo J, Kesselheim AS. Evolution of insulin patents and market exclusivities in the USA. Lancet Diabetes Endocrinol 2015;3:835-7.

37. Kaplan WA, Beall RF. The global intellectual property ecosystem for insulin and its public health implications: an observational study. $J$ Pharm Policy Pract 2017;10:3.

38. Rotenstein LS, Ran N, Shivers JP, et al. Opportunities and challenges for biosimilars: what's on the horizon in the global insulin market? Clinical Diabetes 2012;30:138-50.

39. Chopra R, Lopes G. Improving access to cancer treatments: the role of biosimilars. J Glob Oncol 2017;3:596-610.
40. Beran D, Hirsch IB, Yudkin JS. Why are we failing to address the issue of access to insulin? A national and global perspective. Diabetes Care 2018;41:1125-31.

41. Heinemann L, Khatami $\mathrm{H}$, McKinnon $\mathrm{R}$, et al. An overview of current regulatory requirements for approval of biosimilar insulins. Diabetes Technol Ther 2015;17:510-26.

42. Kuhlmann M, Schmidt A. Production and manufacturing of biosimilar insulins: implications for patients, physicians, and health care systems. Biosimilars 2014;4:45-58.

43. World Health Organization. 2017.WHO to begin pilot prequalification of biosimilars for cancer treatment [article online]. http://www. who.int/mediacentre/news/releases/2017/pilot-prequalificationbiosimilars/en/ (accessed 11 Jun 2017). 